Article

\title{
Electrodeposited Magnesium Nanoparticles Linking Particle Size to Activation Energy
}

\author{
Chaoqi Shen and Kondo-Francois Aguey-Zinsou * \\ Merlin Group, School of Chemical Engineering, The University of New South Wales, Sydney 2052, NSW, \\ Australia; chaoqi.shen@student.unsw.edu.au \\ * Correspondence: f.aguey@unsw.edu.au \\ Academic Editor: Wei-Chiang Hong \\ Received: 15 September 2016; Accepted: 7 December 2016; Published: 16 December 2016
}

\begin{abstract}
The kinetics of hydrogen absorption/desorption can be improved by decreasing particle size down to a few nanometres. However, the associated evolution of activation energy remains unclear. In an attempt to clarify such an evolution with respect to particle size, we electrochemically deposited Mg nanoparticles on a catalytic nickel and noncatalytic titanium substrate. At a short deposition time of $1 \mathrm{~h}$, magnesium particles with a size of $68 \pm 11 \mathrm{~nm}$ could be formed on the nickel substrate, whereas longer deposition times led to much larger particles of $421 \pm 70 \mathrm{~nm}$. Evaluation of the hydrogen desorption properties of the deposited magnesium nanoparticles confirmed the effectiveness of the nickel substrate in facilitating the recombination of hydrogen, but also a significant decrease in activation energy from 56.1 to $37.8 \mathrm{~kJ} \cdot \mathrm{mol}^{-1} \mathrm{H}_{2}$ as particle size decreased from $421 \pm 70$ to $68 \pm 11 \mathrm{~nm}$. Hence, the activation energy was found to be intrinsically linked to magnesium particle size. Such a reduction in activation energy was associated with the decrease of path lengths for hydrogen diffusion at the desorbing $\mathrm{MgH}_{2} / \mathrm{Mg}$ interface. Further reduction in particle size to a few nanometres to remove any barrier for hydrogen diffusion would then leave the single nucleation and growth of the magnesium phase as the only remaining rate-limiting step, assuming that the magnesium surface can effectively catalyse the dissociation/recombination of hydrogen.
\end{abstract}

Keywords: hydrogen storage; magnesium; particle size; nanosize; activation energy

\section{Introduction}

With the purpose of storing hydrogen in a compact and safe form under mild conditions of temperature and pressure, many efforts have been devoted to metal hydrides research. In particular, magnesium has been the focus of extensive investigations, owing to its high gravimetric capacity (7.6 mass \% $\mathrm{H}_{2}$ ) and abundance [1,2]. Currently, magnesium still requires temperatures $>300{ }^{\circ} \mathrm{C}$ to achieve practical storage capacities following the reaction in Equation (1) and, so far, the various alloying strategies explored have had a limited impact on the overall improvements of the thermodynamics of the magnesium/hydrogen reaction [2]. For hydrogen uptake and release close to the ambient temperature, the enthalpy of the reaction needs to be brought down to $\sim 40 \mathrm{~kJ} \cdot \mathrm{mol}^{-1} \mathrm{H}_{2}$ instead of the current $75 \mathrm{~kJ} \cdot \mathrm{mol}^{-1} \mathrm{H}_{2}$.

$$
\mathrm{Mg}+\mathrm{H}_{2} \rightarrow \mathrm{MgH}_{2}+75 \mathrm{~kJ} \cdot \mathrm{mol}^{-1}
$$

Another issue is the slow kinetics for hydrogen release and uptake, owing to the large energy needed to split hydrogen molecules at the magnesium surface (i.e., $432 \mathrm{~kJ} \cdot \mathrm{mol}^{-1} \mathrm{H}_{2}$ ) and the additional energy barrier for hydrogen penetration, the slow diffusion of hydrogen within magnesium $\left(4 \times 10^{-13} \mathrm{~m}^{2} \cdot \mathrm{s}^{-1}\right)$, and the energy barrier for the nucleation and growth of the hydride phase [1]. One approach to overcome the first barrier related to the hydrogen chemisorption and dissociation is 
through doping a surface catalyst with transition metals owing to their d-orbital. Hence, significant improvements have been achieved with transition metals including $\mathrm{Pd}$ and $\mathrm{Ni}$, but also $\mathrm{V}$ and $\mathrm{Nb}$ and their respective oxides [1,3-7]. The latter would be reduced to some extent by magnesium into their metallic counterparts during hydrogen cycling [8]. However, it has also been found that non-transition metals, including $\mathrm{MgO}$, could lead to similar kinetic improvements owing to a reduction in particle sizes $[9,10]$, and thus an increase in surface area and reduction of the length of diffusion paths. In these cases, the improvement of kinetics is possibly due to the reduction of different energy barriers. However, achieving effective hydrogen kinetics at low temperatures would require that all the energy barriers are minimised to some extent, so molecular hydrogen is effectively dissociated at the magnesium surface and rapidly "transported" to form the hydride phase.

An emerging approach toward such a simultaneous control over the various energy barriers involved in the absorption/desorption process of hydrogen in magnesium is through a nanosizing approach (i.e., a reduction of particle size to a few nanometres). Indeed, nanosizing should lead to significant improvements, not only through the reduction of the diffusion distances, but also via easier nucleation and growth processes owing to the higher hydrogen solubility in nanosized magnesium [11]. The overall kinetics would then strongly depend upon the ability of specific magnesium planes to dissociate molecular hydrogen and surface defects [1]. To date, a few reports have shown that, indeed, faster hydrogen kinetics could be achieved via nanosizing [12-14], but the degree to which the associated energy barriers can be minimised remains unclear.

In an attempt to clarify the evolution of activation energy with respect to particle size, we electrochemically deposited $\mathrm{Mg}$ nanoparticles onto a catalytic Ni substrate to facilitate the dissociation of molecular hydrogen and minimise this energy barrier at the magnesium surface. A noncatalytic substrate (Ti) was also used as a reference. The use of a substrate facilitated the "immobilisation" of magnesium nanoparticles against agglomeration and sintering during hydrogen cycling, while avoiding their nanoconfinement, which may lead to additional effects "masking" the evolution of the activation energy as particle size is decreased. Indeed, it has been suggested that the improved hydrogen desorption observed in nanoconfined magnesium particles may be related to additional clamping effects, inducing interfacial and mechanical stress on the magnesium nanoparticles [15]. The porous carbon host/magnesium interface is another factor that may lead to intermediate/mixed phases, including oxides owing to oxygen surface groups at carbon surfaces [16,17]. Herein, we report on the synthesis of magnesium nanoparticles supported on a substrate and thus free from any confinement effects from encapsulation within a porous matrix, and the evolution of activation energy as function of particle size.

\section{Materials and Methods}

All operations were carried out under an inert atmosphere in an argon-filled LC Technology glove box $\left(<1\right.$ ppm $\mathrm{O}_{2}$ and $\left.\mathrm{H}_{2} \mathrm{O}\right)$.

\subsection{Materials}

Di-n-butylmagnesium $\left(\mathrm{MgBu}_{2}\right)$ was purchased from Sigma-Aldrich and tetrabutylammonium bromide (TBAB) from Fluka. TBAB was dried under vacuum at $50{ }^{\circ} \mathrm{C}$ prior to use. Tetrahydrofuran (THF) was purchased as HPLC grade from Fisher Scientific and dried using an LC Technology SP-1 Solvent Purification System. Magnesium (Mg) ribbon, titanium (Ti) foil, platinum (Pt) wire, and nickel (Ni) foam were purchased from Goodfellow. Ni foam was used instead of a foil to increase surface area. The surface of the Ni foam was cleaned by treating the foam for $1 \mathrm{~h}$ under a hydrogen flow of $20 \mathrm{~mL} \cdot \mathrm{min}^{-1}$ at $300{ }^{\circ} \mathrm{C}$. The surfaces of $\mathrm{Mg}$ and Ti were polished with abrasive paper and washed with THF to remove the oxide layer. 


\subsection{Synthesis of Supported Magnesium Nanoparticles}

The magnesium nanoparticles were electrochemically deposited on $\mathrm{Ti}$ and Ni substrates. To this aim, a three-electrode cell was used with the $\mathrm{Mg}$ ribbon acting as the counter electrode, the $\mathrm{Ni}$ foam or Ti foil as the working electrode, and a Pt wire as the reference electrode. The electrolyte consisted of $18 \mathrm{~mL}$ THF solution of $20 \mathrm{mM}$ di-n-butylmagnesium and $20 \mathrm{mM}$ TBAB. TBAB was used to facilitate the deposition of the $\mathrm{Mg}$ nanoparticles and to act as a supporting electrolyte. Electrochemical deposition was performed by applying a current of $-1 \mathrm{~mA}$ between the working and counter electrode using a Biologic VMP3 potentiostat. At the end of the deposition process, the Ni foam and Ti foil were washed with THF and dried under vacuum on a Schlenk line. Finally, the supported Mg nanoparticles were hydrogenated under a hydrogen pressure of $3 \mathrm{MPa}$ at $200^{\circ} \mathrm{C}$ on a homemade Sievert apparatus to lead $\mathrm{MgH}_{2}$. The amount of magnesium deposited on the Ni foam after $5 \mathrm{~h}$ was determined by inductively coupled plasma optical emission spectroscopy (ICP-OES) with a PerkinElmer OPTIMA 7300 ICP-OES instrument (Supplementary Materials, Figure S1). Prior to analysis, the material (100 mg) was dissolved into $400 \mu \mathrm{L}$ of concentrated hydrochloric acid and diluted 20 times with high-purity water. According to ICP analysis, the Ni-foam substrate, after $5 \mathrm{~h}$ of deposition, contained $1.7 \pm 0.1 \mathrm{mass} \%$ of $\mathrm{Mg}$, which corresponds to an overall storage capacity of $0.13 \pm 0.01$ mass $\% \mathrm{H}_{2}$ for the material based on $\mathrm{Mg}$.

\subsection{Magnesium Nanoparticles Characterisation}

The morphology characterisation, energy dispersive X-ray spectroscopy (EDX), and elemental mapping of the supported magnesium particles was performed by field emission scanning electron microscopy using an FEI Nova NanoSEM 450. The materials were taken to the microscope in a closed vial under high-purity argon and transferred in air to the microscope. The size of $\sim 50$ particles was manually measured and a statistical analysis was carried out to obtain the size distribution and mean particle size.

The crystalline nature of the materials was determined by X-ray diffraction (XRD) using a Philips X'pert Multipurpose XRD system operated at $40 \mathrm{~mA}$ and $45 \mathrm{kV}$ with a monochromated $\mathrm{Cu} \mathrm{Ka}$ radiation $(\lambda=1.541 \AA)$-step size $=0.01,0.02$, or 0.05 ; time per step $=10$ or $20 \mathrm{~s} \cdot \mathrm{step}^{-1}$. The materials were protected against oxidation from air by a Kapton foil.

Hydrogen desorption profiles were determined by using thermogravimetric analysis (TGA) coupled with mass spectrometry (MS). Desorptions were conducted under an argon flow of $20 \mathrm{~mL} \cdot \mathrm{min}^{-1}$ at 5,10 , and $20^{\circ} \mathrm{C} \cdot \mathrm{min}^{-1}$ using a Mettler Toledo TGA/DSC coupled with an OmniStar MS. Masses between $m / z=2$ and 100 were followed ( $m / z$ represents the mass-to-charge ratio).

Hydrogen desorption kinetics were characterised using a high-pressure magnetic balance of $1 \mu \mathrm{g}$ resolution equipped with capability for simultaneous density measurements (Rubotherm). Around $30 \mathrm{mg}$ of material was used, with a hydrogen pressure of $3 \mathrm{MPa}$ for absorption and $0.01 \mathrm{MPa}$ for desorption. Hydrogen uptake and release were determined from the weight changes. For an accurate determination of the amount of hydrogen stored, a blank measurement with the empty sample holder was performed to determine the mass and volume of the sample holder. Further measurements were performed under a helium atmosphere with the material fully desorbed to determine the density of the materials and corresponding parameters for buoyancy corrections. The hydrogen absorption was performed at $150{ }^{\circ} \mathrm{C}$ under $3 \mathrm{MPa} \mathrm{H}_{2}$ pressure, and desorption was carried at 150,200 , and $250{ }^{\circ} \mathrm{C}$ under a pressure of $0.01 \mathrm{MPa}$.

\section{Results and Discussions}

To date, only a few groups have reported on the electrochemical synthesis of magnesium-based hydrogen storage materials [18-20], owing to the low reduction potential of the $\mathrm{Mg}^{2+} / \mathrm{Mg}$ couple $(-2.37 \mathrm{~V}$ vs normal hydrogen electrode (NHE)) and the difficulty of reducing magnesium salts by electrochemical means. Magnesium cannot be deposited from common salts, including halides, perchlorates, or ethoxides [21]. However, it has been known for sometimes that Grignard reagents 
$\left(\mathrm{MgR}_{2}\right.$ or $\mathrm{MgRX}$, where $\mathrm{R}$ is an alky or aryl group and $\mathrm{X}$ is a halide) could lead to the effective plating of magnesium at surfaces [22-24], following the electrochemical deposition paths [25].

With $\mathrm{MgR}_{2}$ :

$$
\begin{aligned}
2 \mathrm{MgR}_{2}+2 \mathrm{e} & \rightleftarrows 2 \mathrm{RMg}^{\bullet}{ }_{(\mathrm{ad})}+2 \mathrm{R}^{-} \\
2 \mathrm{RMg}^{\bullet}{ }_{(\mathrm{ad})} & \rightleftarrows \mathrm{Mg}+\mathrm{MgR}_{2(\mathrm{sol})}
\end{aligned}
$$

or with $\mathrm{RMgX}$ :

$$
\begin{gathered}
2 \mathrm{RMgX} \rightleftarrows \mathrm{MgR}_{2}+\mathrm{MgX}_{2} \text { Schlenk equilibrium } \\
2 \mathrm{RMgX} \rightleftarrows \mathrm{RMg}^{+}+\mathrm{RMgX}_{2}{ }^{-} \text {Ionisation equilibrium } \\
\mathrm{RMg}^{+}+2 \mathrm{e} \rightleftarrows 2 \mathrm{RMg}_{(\mathrm{ad})}
\end{gathered}
$$

or

$$
\begin{gathered}
2 \mathrm{MgR}_{2}+2 \mathrm{e}^{-} \rightleftarrows 2 \mathrm{RMg}^{\bullet}{ }_{(\mathrm{ad})} \\
2 \mathrm{RMg}^{\bullet}{ }_{(\mathrm{ad})} \rightleftarrows \mathrm{Mg}+\mathrm{MgR}_{2(\mathrm{sol})}
\end{gathered}
$$

where "ad" corresponds to adsorption and "sol" to solution.

In order to minimise the codeposition of halides, we opted for di- $n$-butylmagnesium. The latter can also be used to generate magnesium hydride through its thermolysis route $[13,26]$, and thus provides additional means for comparison with respect to the hydrogen properties of electrochemically synthesised magnesium.

\subsection{Electrochemical Deposition of Magnesium Nanoparticles and Structural Properties}

Cyclic voltammograms were first acquired to confirm the deposition conditions for the different substrates. As shown Figure $1 \mathrm{a}, \mathrm{b}, \mathrm{Mg}$ was effectively deposited and reoxidised within a broad electrochemical window as per previous reports [27]. On both $\mathrm{Ni}$ and $\mathrm{Ti}$, the addition of TBAB as a supporting electrolyte reduced the intensity of the reoxidation peak, indicating a better ability to form more strongly bonded $\mathrm{Mg}$ deposits [28]. It is noteworthy that the reduction current at the Ni foam was higher when compared to the Ti foil, and this was attributed to the higher surface area of the foam. Following the cyclic voltammogram, a current of $-1 \mathrm{~mA}$ was used to ensure rapid nucleation and growth of the magnesium phase at the surface of the substrate.
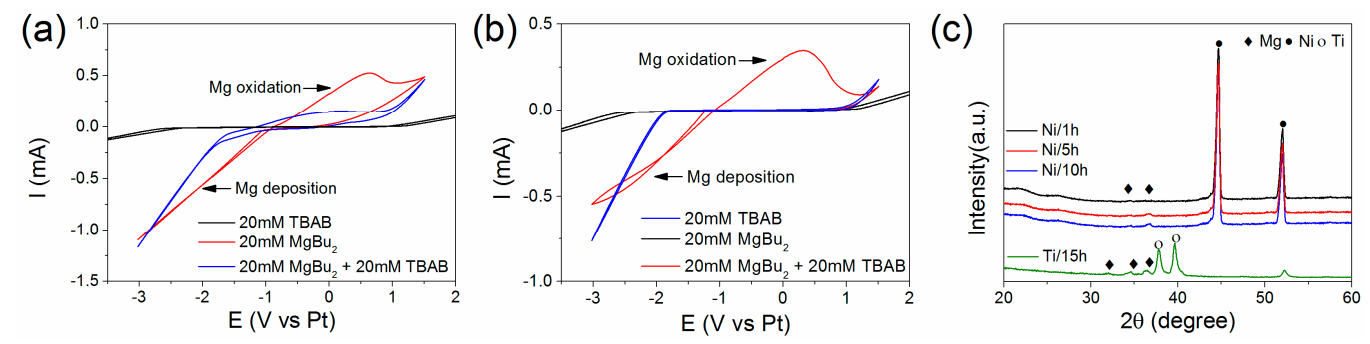

Figure 1. Cyclic voltammogram of di-n-butylmagnesium $\left(\mathrm{MgBu}_{2}\right)$ with and without tetrabutylammonium bromide (TBAB) at (a) the Ni foam electrode and (b) the Ti foil electrode; and (c) associated X-ray diffraction (XRD) at different deposition times.

After electrochemical deposition of magnesium, analysis by XRD confirmed that the electrodeposited material corresponded to hexagonal magnesium with very broad diffraction peaks only visible after a long deposition time (Figure 1c). The low intensity and broadness of these diffraction peaks suggested the formation of nanocrystalline magnesium particles.

Indeed, additional analysis of the Ni substrate by SEM confirmed the uniform deposition of small magnesium particles with an average size of $68 \pm 11 \mathrm{~nm}$ after $1 \mathrm{~h}$ of deposition. Longer deposition times led to the growth of these nanoparticles up to an average size of $421 \pm 70 \mathrm{~nm}$ after $10 \mathrm{~h}$ of 
deposition (Figure 2 and Table 1). Similar deposition time on the Ti substrate led to a more rapid deposition of magnesium. After $1 \mathrm{~h}$, a relatively thick film of agglomerated magnesium particles with an average size of $341 \pm 60 \mathrm{~nm}$ was already observed (Figure 3 and Table 1); and this suggested an easier deposition of magnesium on $\mathrm{Ti}$ and/or different nucleation and growth of the deposited magnesium phase. Indeed, longer deposition times led to the formation of "mushroom"-like structures of several microns (Figure 3c).
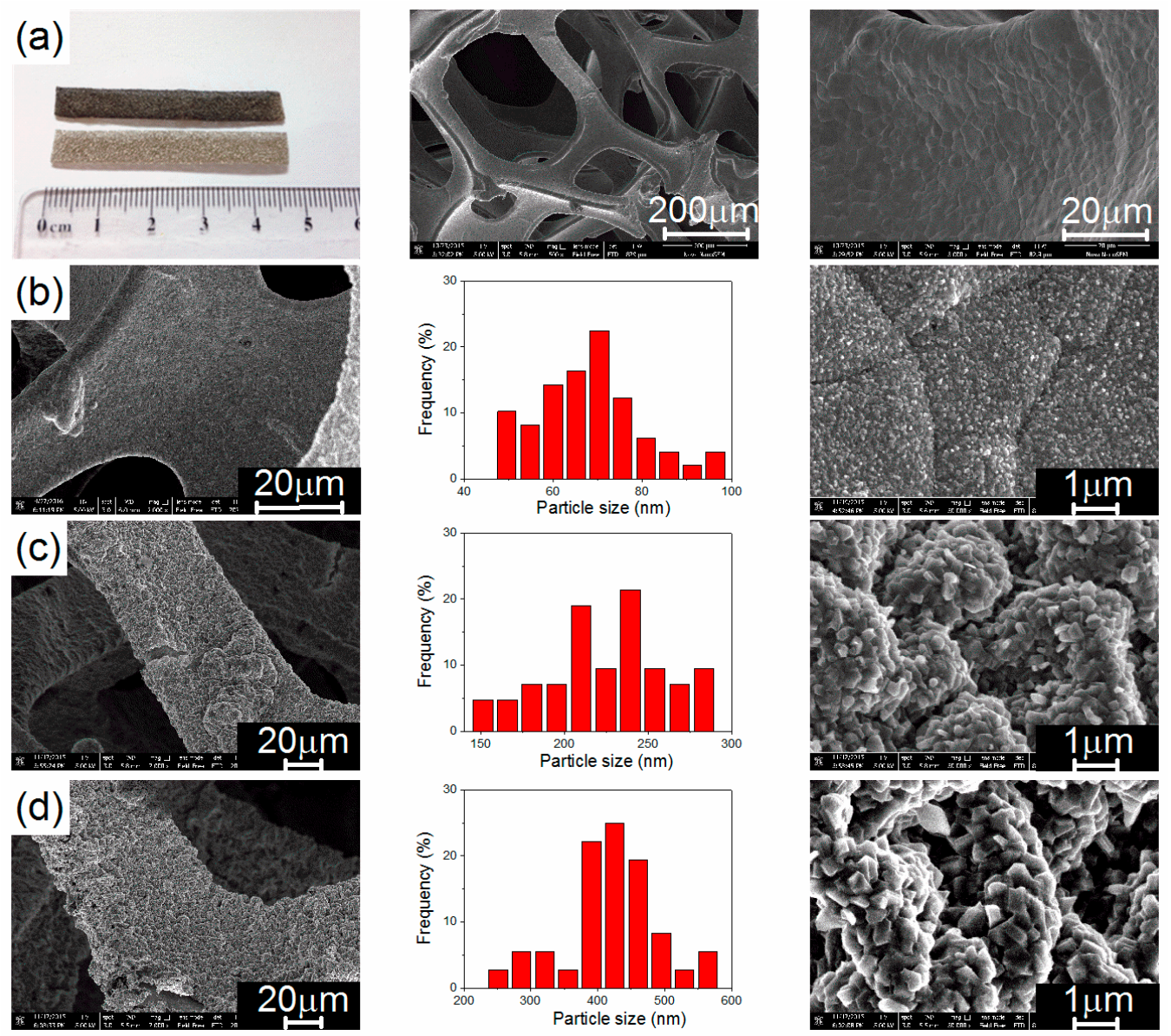

Figure 2. (a) Photo and typical SEM images of the pristine Ni foam; and typical SEM images and particle-size distribution of the magnesium nanoparticles obtained at different deposition times (b) $1 \mathrm{~h}$; (c) $5 \mathrm{~h}$; and (d) $10 \mathrm{~h}$ of di- $n$-butylmagnesium at the Ni surface.

Table 1. Summary of the physical and hydrogen desorption properties of the magnesium nanoparticles deposited on Ni and Ti. Particle size was determined by SEM, crystallite size by the Scherrer equation, and activation energy $\left(\mathrm{E}_{\mathrm{a}}\right)$ by using the Kissinger method.

\begin{tabular}{|c|c|c|c|c|c|}
\hline Substrate & $\begin{array}{l}\text { Deposition } \\
\text { Time (h) }\end{array}$ & $\begin{array}{l}\text { Particle Size } \\
\quad(n m)\end{array}$ & $\begin{array}{l}\text { Crystallite } \\
\text { Size }(\mathrm{nm})\end{array}$ & $\begin{array}{c}\mathrm{H}_{2} \text { Desorption } \\
\text { Temperature }\left({ }^{\circ} \mathrm{C}\right)\end{array}$ & $\begin{array}{c}\mathrm{E}_{\mathrm{a}} \\
\left(\mathrm{kJ} \cdot \mathrm{mol}^{-1} \mathrm{H}_{2}\right)\end{array}$ \\
\hline \multirow{3}{*}{$\mathrm{Ni}$} & 1 & $68 \pm 11$ & - & 295 & $37.8 \pm 0.7$ \\
\hline & 5 & $225 \pm 35$ & $12 \pm 2$ & 330 & $49.4 \pm 2.1$ \\
\hline & 10 & $421 \pm 70$ & $14 \pm 2$ & 390 & $56.1 \pm 4.2$ \\
\hline \multirow{2}{*}{$\mathrm{Ti}$} & 1 & $341 \pm 60$ & - & 380 & $125.4 \pm 2.6$ \\
\hline & 15 & - & $14 \pm 2$ & 385 & $240.1 \pm 12.7$ \\
\hline
\end{tabular}


(a)
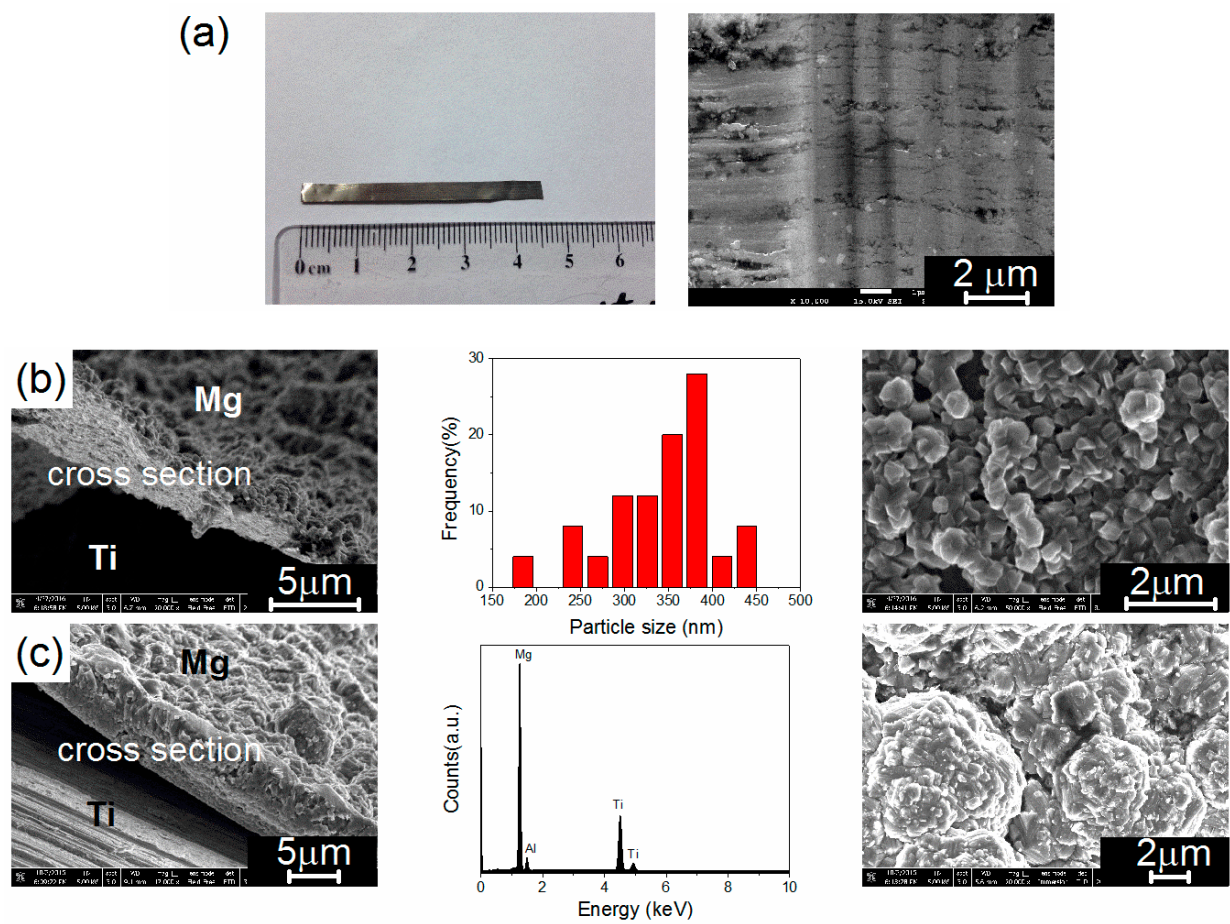

Figure 3. (a) Photo and typical SEM images of the pristine Ti foil; and typical SEM images and particle size distribution of the magnesium nanoparticles obtained at different deposition times (b) $1 \mathrm{~h}$ and (c) $15 \mathrm{~h}$ of di- $n$-butylmagnesium at the Ti surface.

\subsection{Hydrogen Sorption Properties}

In order to assess the hydrogen sorption properties of the magnesium nanoparticles deposited at the $\mathrm{Ni}$ and Ti substrates, the materials were first hydrogenated at $200^{\circ} \mathrm{C}$ under a hydrogen pressure of $3 \mathrm{MPa}$. At this temperature, the magnesium deposits were found to be stable (Figure 4a). However, at a higher temperature of $300{ }^{\circ} \mathrm{C}$ the film of the agglomerated magnesium nanoparticles started to degrade (Figure $4 \mathrm{~b}$ ). After hydrogenation at $200{ }^{\circ} \mathrm{C}, \mathrm{XRD}$ analysis confirmed that the magnesium deposited on the Ti substrate for $15 \mathrm{~h}$ was fully hydrogenated (Figure S2), hence we assumed that full hydrogenation was also occurring for the smaller magnesium particles with very weak to no XRD diffraction peaks (i.e., Ni/1 h-10 h, Figure 1c).
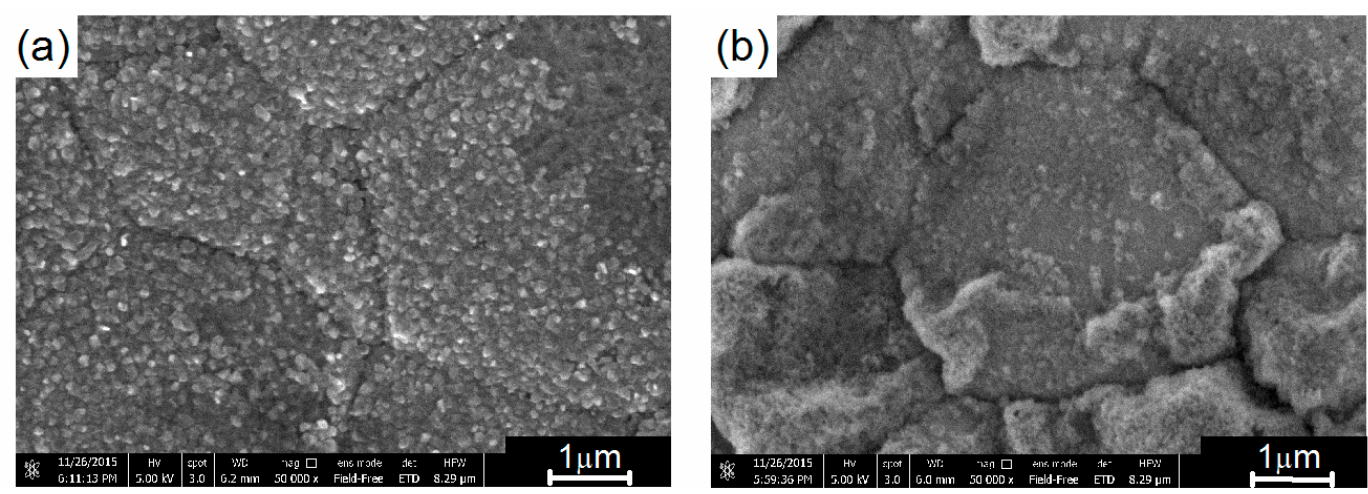

Figure 4. Typical SEM images of the film of magnesium nanoparticles obtained after $5 \mathrm{~h}$ of electrochemical deposition on $\mathrm{Ni}$ and subsequent hydrogenation at (a) $200{ }^{\circ} \mathrm{C}$ and (b) $300{ }^{\circ} \mathrm{C}$ and $3 \mathrm{MPa}$ hydrogen pressure. 
The hydrogenated materials were then analysed by TGA/MS to determine their hydrogen desorption profiles. As shown Figure 5a, deposition of $1 \mathrm{~h}$ onto the Ni substrate led to the lowest hydrogen desorption temperature. The latter started at $210^{\circ} \mathrm{C}$ with a peak at $295^{\circ} \mathrm{C}$. Higher deposition times led to an increase in the temperature at which hydrogen was released (Figure 5a), but remarkably the onset for hydrogen release remained at $210{ }^{\circ} \mathrm{C}$. This may be regarded as the initial point to trigger hydrogen desorption and thus was assigned to the catalytic effect of the Ni substrate in facilitating the recombination of hydrogen atoms at the magnesium surface $[29,30]$. Indeed, on the noncatalytic Ti substrate, the onset temperatures for hydrogen desorption significantly differed (by $50{ }^{\circ} \mathrm{C}$ ) as particle size increased and the surface area decreased accordingly (Figure $5 \mathrm{~b}$ ), in agreement with previous reports [15]. The initial desorption of hydrogen at $210^{\circ} \mathrm{C}$ is also consistent with reported thermal desorption spectra of molecular hydrogen adsorbed at Ni surfaces [31-33]. It can thus be concluded that the shift in desorption temperature observed on the Ni catalytic substrate from 290 to $390{ }^{\circ} \mathrm{C}$ as particle size increased from $68 \pm 11$ to $421 \pm 70 \mathrm{~nm}$ is related to rate-limiting steps other than hydrogen recombination at the magnesium surface.

(a)

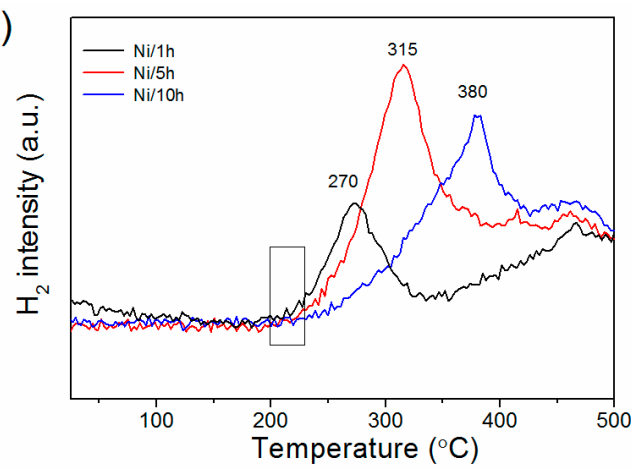

(b)

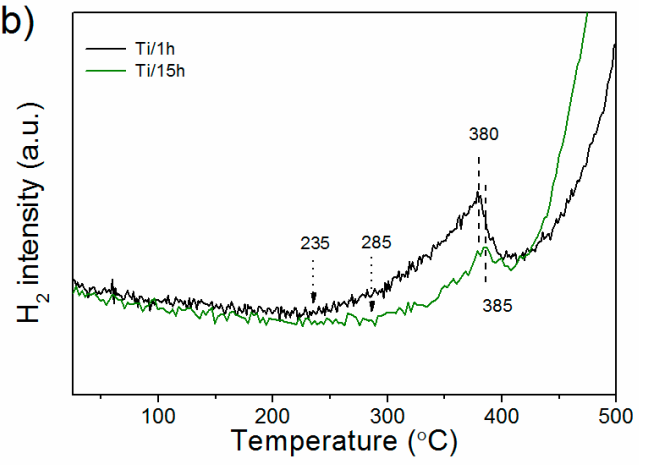

Figure 5. Hydrogen desorption profile of the magnesium nanoparticles deposited on (a) Ni and (b) Ti. Hydrogenation was carried out at $200{ }^{\circ} \mathrm{C}$ and $3 \mathrm{MPa}$ hydrogen pressure. Additional hydrogen desorption $>400{ }^{\circ} \mathrm{C}$ was assigned to the reduction of hydroxyls groups at the Ni surface (Figure S3). [34] The increase in signal above $400{ }^{\circ} \mathrm{C}$ on the Ti substrate corresponds to a drift of the baseline.

In order to determine the evolution of the overall activation energy $\left(E_{a}\right)$ of the hydrogen desorption process, hydrogen desorption profiles were measured by MS at different rates (Figure S4) and the $E_{a}$ determined from the Kissinger's equation (Figure 6a). The results are summarised in Table 1 and Figure $6 \mathrm{~b}$. Remarkably, $\mathrm{E}_{\mathrm{a}}$ was found to be significantly lower on the catalytic Ni substrates than Ti. For example, the $341 \pm 60 \mathrm{~nm}$ magnesium particles on the Ti substrate had an $E_{a}$ of $125.4 \pm 2.6 \mathrm{~kJ} \cdot \mathrm{mol}^{-1}$ $\mathrm{H}_{2}$, which is more than twice the activation energy of the $421 \pm 70 \mathrm{~nm}$ magnesium particles at the $\mathrm{Ni}$ substrate. This is in agreement with previous reports showing a significant reduction of the activation energy when $\mathrm{Ni}$ is incorporated in the $\mathrm{Mg} / \mathrm{MgH}_{2}$ system to minimise the first initial energy barrier of hydrogen dissociation/recombination at the magnesium surface. For example, Hanada et al. reported the significant decrease in $\mathrm{E}_{\mathrm{a}}$ from $323 \pm 40$ to $94 \pm 3 \mathrm{~kJ} \cdot \mathrm{mol}^{-1} \mathrm{H}_{2}$ upon incorporation of nanosized $\mathrm{Ni}$ to ball-milled $\mathrm{MgH}_{2}$ [29]. It is noteworthy that for the smallest particle size of $68 \pm 11 \mathrm{~nm}, \mathrm{E}_{\mathrm{a}}$ decreased to $37.8 \pm 0.7 \mathrm{~kJ} \cdot \mathrm{mol}^{-1} \mathrm{H}_{2}$ and, to the best of our knowledge, this is the lowest activation energy observed for the release of hydrogen from $\mathrm{MgH}_{2}$. Low activation energies have also been reported for other systems (e.g., on Cr-catalysed magnesium thin films a value of $65.7 \mathrm{~kJ} \cdot \mathrm{mol}^{-1}$ was reported [35]), while values ranging from 45.67 to $118 \mathrm{~kJ} \cdot \mathrm{mol}^{-1}$ have been reported for catalysed or uncatalysed ball-milled $\mathrm{MgH}_{2}$ [36-39]. Such a decrease in $\mathrm{E}_{\mathrm{a}}$ could be assigned to reduced particle sizes in addition to the catalytic effect of $\mathrm{Ni}$ and/or additional contribution for varying crystallite sizes [40]. However, additional determination of the crystallite size by using the Scherrer equation reveals similar crystallite sizes for the magnesium particles deposited at the $\mathrm{Ni}$ and $\mathrm{Ti}$ substrates (Table 1). Hence, the decrease in $\mathrm{E}_{\mathrm{a}}$ observed was assigned to the sole effect of particle size. 

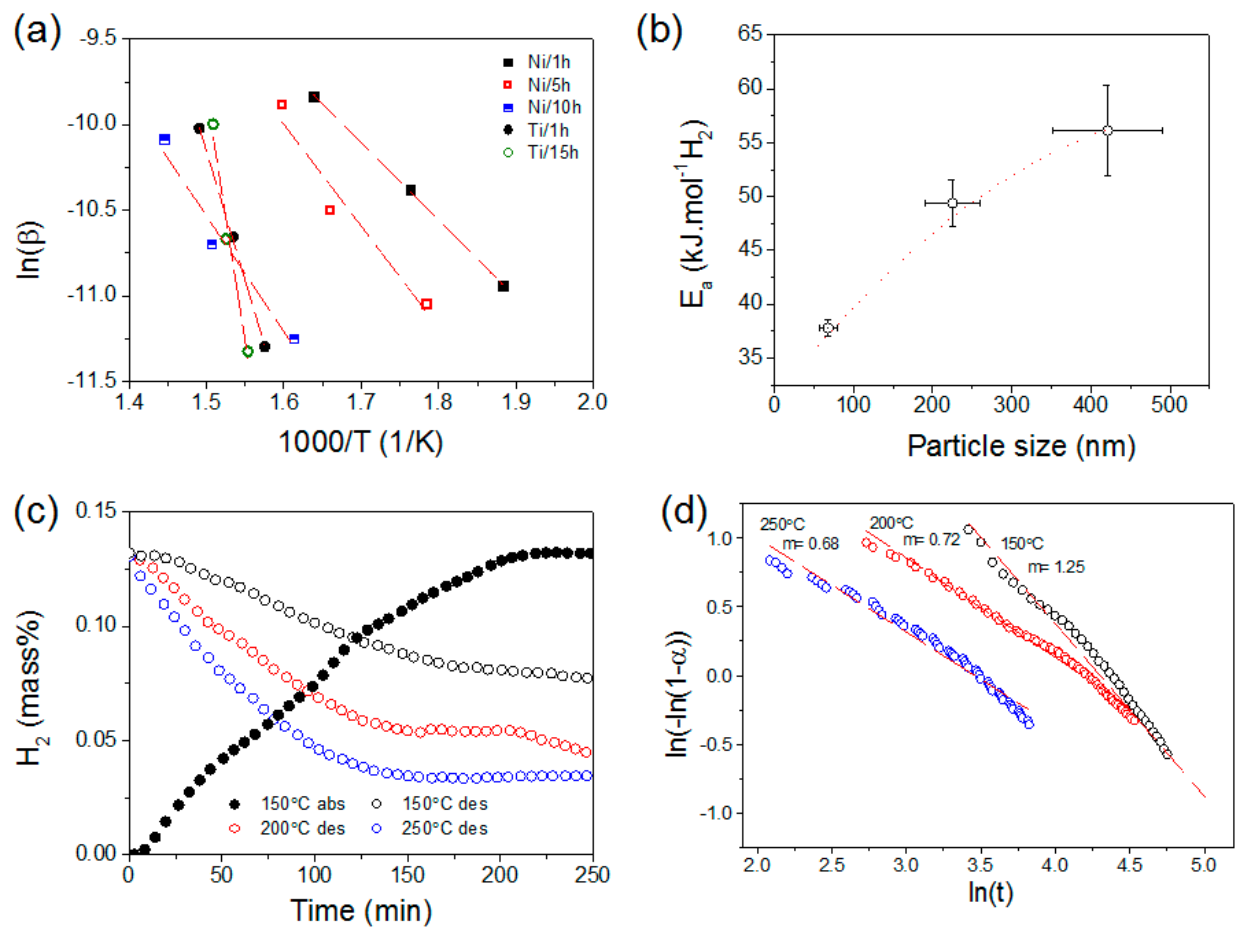

Figure 6. (a) Kissinger plot related to the hydrogen desorption from the magnesium nanoparticles deposited on $\mathrm{Ni}$ and $\mathrm{Ti}$; (b) associated activation energy $\left(\mathrm{E}_{\mathrm{a}}\right)$ as function of magnesium's average particle size on the Ni substrates at 1, 5, and $10 \mathrm{~h}$ deposition time; (c) hydrogen kinetics for the material obtained after $5 \mathrm{~h}$ of electrochemical deposition; and (d) associated fit of the hydrogen kinetic desorption curves obtained at 150,200 , and $250{ }^{\circ} \mathrm{C}$.

Similarly on the Ti substrate, $\mathrm{E}_{\mathrm{a}}$ was found to decrease with particle size (Table 1). Like other systems including palladium [41], sodium alanate [42], and lithium amide [43]. It is thus apparent that $E_{a}$ depends upon magnesium's particle size, with the initial step of hydrogen dissociation/recombination as the main rate-limiting step. However, once this barrier is minimised though the use of a catalyst, additional rate-limiting steps will remain in the form of the hydrogen penetration, diffusion, and nucleation and growth of the hydride phase.

In order to determine the initial rate-limiting step of the hydrogen desorption process from the magnesium nanoparticles and assess the potential catalytic effect of the Ni substrate, the materials after $5 \mathrm{~h}$ deposition was cycled and the kinetics curves obtained were fitted using the general equation of a solid-state reaction (9) [44]:

$$
\mathrm{G}(\alpha)=\mathrm{k} \times \mathrm{t}
$$

where $\alpha$ is the amount of hydrogen released in time $t, k=k(T, P, r)$ is the reaction rate, and $G(\alpha)$ is a function depending on the mechanism controlling the reaction. The main theoretical functions $G(\alpha)$ are summarised in Table 2. In order to facilitate the fitting of the hydrogen curves measured and ease the distinction of reaction mechanisms, the method of Hancock and Sharp was used [45]. Since nucleation and growth processes in condensed systems follow the almost universal Equation (10), the method consists of plotting $\ln (-\ln (1-\alpha))$ versus $\ln (t)$.

$$
\alpha=1-\exp \left(-\mathrm{Bt}^{\mathrm{m}}\right)
$$

where $B$ is a constant that depends on the nucleation frequency and linear rate of the grain growth, and $\mathrm{m}$ is a constant that varies according to the geometry of the system. Hence, determining the value of $\mathrm{m}$ would indicate the main rate-limiting step of the hydrogen desorption process. 
Table 2. Summary of main model functions describing solid-gas kinetics.

\begin{tabular}{|c|c|c|}
\hline Mechanism & Functional Time Dependence G $(\alpha)$ & $\mathbf{m}$ \\
\hline \multicolumn{3}{|c|}{ Surface control } \\
\hline $\mathrm{S}_{1}$ & $\alpha$ & 1.24 \\
\hline \multicolumn{3}{|c|}{ Random nucleation and growth (Avrami equations) } \\
\hline $\mathrm{A}_{1}$ & {$[-\ln (1-\alpha)]^{1 / 4}$} & 4.00 \\
\hline $\mathrm{A}_{2}$ & {$[-\ln (1-\alpha)]^{1 / 3}$} & 3.00 \\
\hline $\mathrm{A}_{3}$ & {$[-\ln (1-\alpha)]^{2 / 5}$} & 2.50 \\
\hline $\mathrm{A}_{4}$ & {$[-\ln (1-\alpha)]^{1 / 2}$} & 2.00 \\
\hline $\mathrm{A}_{5}$ & {$[-\ln (1-\alpha)]^{2 / 3}$} & 1.50 \\
\hline \multicolumn{3}{|c|}{ Shrinking core with constant velocity: controlled by interface reaction } \\
\hline $\mathrm{IP}_{2}$ - contracting surface & $1-(1-\alpha)^{1 / 2}$ & 1.11 \\
\hline $\mathrm{IP}_{3}$-contracting volume & $1-(1-\alpha)^{1 / 3}$ & 1.07 \\
\hline \multicolumn{3}{|c|}{ Shrinking core with decelerating velocity: controlled by diffusion } \\
\hline $\mathrm{D}_{1}-1-\mathrm{D}$ diffusion & $\alpha^{2}$ & 0.62 \\
\hline $\mathrm{D}_{2}-2-\mathrm{D}$ diffusion & $(1-\alpha) \ln (1-\alpha)+\alpha$ & 0.57 \\
\hline $\mathrm{D}_{3}$-Jander, 3-D diffusion & $\left(1-(1-\alpha)^{1 / 3}\right)^{2}$ & 0.54 \\
\hline
\end{tabular}

Such an analysis was only possible for the material after $5 \mathrm{~h}$ electrochemical deposition, owing to the minimum amount of magnesium required to obtained meaningful kinetic curves and the need for relatively low hydrogen desorption temperatures to avoid any significant degradation of the magnesium film. Figure $6 \mathrm{c}, \mathrm{d}$ show the hydrogen kinetics of the magnesium nanoparticles at different temperatures after initial hydrogen absorption at $150{ }^{\circ} \mathrm{C}$, and the associated fits following the method of Hancock and Sharp [45] for $\alpha$ values comprised between 0.1 and 0.5 to minimise uncertainties related to the initial conditions of desorption, as well as any variations related to particle-size distribution and other geometrical effects. At the low temperature of $150{ }^{\circ} \mathrm{C}$, the hydrogen desorption kinetics were slow and the slope of the fit was found to be close to $\mathrm{m}=1.25$ (Figure 6d), which indicates that the desorption process is surface-controlled. This is in agreement with the hydrogen desorption profiles observed at the $\mathrm{Ni}$ substrate (Figure $5 \mathrm{a}$ ) and the significant hydrogen evolution happening for temperatures above $210{ }^{\circ} \mathrm{C}$.

At higher temperatures, the hydrogen desorption kinetics were faster, and the slope of the fits shifted to values of $\mathrm{m}=0.72$ at $200{ }^{\circ} \mathrm{C}$ and $\mathrm{m}=0.68$ at $250{ }^{\circ} \mathrm{C}$ (Figure $6 \mathrm{~d}$ ). The rate-limiting step was thus assigned to a shrinking core model controlled by diffusion (i.e., the desorption is controlled by the reaction at the $\mathrm{Mg} / \mathrm{MgH}_{2}$ shrinking core interface with the interface reaction proceeding at constant velocity and not the surface anymore). Hence, for the magnesium particle of $225 \pm 35 \mathrm{~nm}$, at low temperatures $\left(<210^{\circ} \mathrm{C}\right)$ the hydrogen desorption kinetics would be controlled by the ability of the surface to recombine hydrogen, while at higher temperatures (where this is facilitated by $\mathrm{Ni}$ ), the main rate-limiting step would be the diffusion of hydrogen at the $\mathrm{Mg} / \mathrm{MgH}_{2}$ interface. As particle size is reduced, such a rate-limiting step should be facilitated in agreement with the reduction in $E_{a}$ observed (Table 1).

Previous investigations have shown that for bigger magnesium particles of a few micrometres prepared by ball-milling, the rate-limiting step is mainly controlled by the growth of several nuclei and thus the associated nucleation and growth process [1]. For much smaller magnesium particles of a few hundred nanometres it can be assumed that single nuclei will be formed and thus the reaction will then be controlled by diffusion, as currently found. Hence, improving the hydrogen kinetics will require finding effective additives to enhance the diffusion of hydrogen or synthesise novel magnesium nanocrystalline structures with enhanced hydrogen diffusion. At much smaller particle sizes of a few nanometres, the process has been reported to be controlled by nucleation and growth, owing the 
extremely short diffusion distances and the large surface area [20]. Hence, additional improvement will require an adequate catalyst to facilitate this process.

\section{Conclusions}

The electrochemical deposition of magnesium from the reduction of di- $n$-butylmagnesium on $\mathrm{Ni}$ and Ti substrates was used to generate magnesium nanoparticles of various sizes, and thus evaluate the evolution of $\mathrm{E}_{\mathrm{a}}$ for the decomposition of $\mathrm{MgH}_{2}$ as a function of particle size. On the Ni substrate, magnesium particles with various sizes (ranging from $68 \pm 11 \mathrm{~nm}$ to $421 \pm 70 \mathrm{~nm}$ ) were synthesised, and these particles showed a significant decrease in $E_{a}$ as particle size decreased. Hence, $\mathrm{E}_{\mathrm{a}}$ was reduced from 56.1 to $37.8 \mathrm{~kJ} \cdot \mathrm{mol}^{-1} \mathrm{H}_{2}$ as magnesium particle size was reduced from $421 \pm 70$ to $68 \pm 11 \mathrm{~nm}$. $\mathrm{E}_{\mathrm{a}}$ on the Ni substrate $\left(56.1 \mathrm{~kJ} \cdot \mathrm{mol}^{-1} \mathrm{H}_{2}\right)$ was found to be much lower than on the Ti substrate $\left(125.4 \mathrm{~kJ} \cdot \mathrm{mol}^{-1} \mathrm{H}_{2}\right)$ at similar particle sizes. More remarkably, $\mathrm{E}_{\mathrm{a}}$ was found to depend upon particle size of magnesium with the initial step of hydrogen dissociation/recombination as the main rate-limiting step. However, once this barrier was minimised through Ni catalysis, the main rate-limiting step was found to be related to the hydrogen diffusion toward the desorbing $\mathrm{MgH}_{2} / \mathrm{Mg}$ interface. It is thus apparent that upon appropriate catalysis of the hydrogen dissociation/recombination, fast hydrogen kinetics should be feasible with very small magnesium particles. Assuming that similar improvements can be achieved with respect to the thermodynamic of the magnesium/hydrogen reaction, the approach of nanosizing may lead to an effective route toward room-temperature magnesium-based materials for hydrogen storage.

Supplementary Materials: The following are available online at www.mdpi.com/1996-1073/9/12/1073/s1, Figure S1: Amount of magnesium deposition at the surface of the Ni foam as function of time and corresponding charge passed through the electrochemical cell. The amount of magnesium was determined from ICP-OES analysis, Figure S2: XRD pattern of Ti/ $15 \mathrm{~h}$ after $200^{\circ} \mathrm{C}$ hydrogenation, Figure S3: Hydrogen desorption profile of the Ni foam, Figure S4: Hydrogen desorption profiles obtained by MS at various heating rates $\left(5,10\right.$, and $\left.20^{\circ} \mathrm{C} \cdot \mathrm{min}^{-1}\right)$ of the magnesium nanoparticle deposited at the $\mathrm{Ni}$ and $\mathrm{Ti}$ substrates. Only the first peak corresponding to hydrogen release from the magnesium nanoparticles supported on the Ni substrate was used to calculate $\mathrm{E}_{\mathrm{a}}$.

Acknowledgments: This research was supported by UNSW Internal Research Grant program. We appreciate the use of instruments at the Mark Wainwright Analytical Centre at UNSW. We are grateful to Simon Hager from the Mark Wainwright Analytical Centre at UNSW for the help with the SEM analysis.

Author Contributions: All the authors contributed equally to this work.

Conflicts of Interest: The authors declare no conflict of interest.

\section{References}

1. Aguey-Zinsou, K.-F.; Ares-Fernández, J.-R. Hydrogen in magnesium: New perspectives toward functional stores. Energy Environ. Sci. 2010, 3, 526-543. [CrossRef]

2. Sakintuna, B.; Lamari-Darkrim, F.; Hirscher, M. Metal hydride materials for solid hydrogen storage: A review. Int. J. Hydrogen Energy 2007, 32, 1121-1140. [CrossRef]

3. Bobet, J.L.; Kandavel, M.; Ramaprabhu, S. Effects of ball-milling conditions and additives on the hydrogen sorption properties of $\mathrm{Mg}+5 \mathrm{wt} \% \mathrm{Cr}_{2} \mathrm{O}_{3}$ mixtures. J. Mater. Res. 2011, 21, 1747-1752. [CrossRef]

4. Bobet, J. Study of $\mathrm{Mg}-\mathrm{M}(\mathrm{M}=\mathrm{Co}, \mathrm{Ni}$ and $\mathrm{Fe})$ mixture elaborated by reactive mechanical alloying-Hydrogen sorption properties. Int. J. Hydrogen Energy 2000, 25, 987-996. [CrossRef]

5. Song, M.; Kwon, S.; Hong, S.-H.; Park, H. Hydrogen storage properties of a Ni, Fe and Ti-added Mg-based alloy. Met. Mater. Int. 2012, 18, 279-286. [CrossRef]

6. Liu, T.; Chen, C.; Wang, H.; Wu, Y. Enhanced hydrogen storage properties of Mg-Ti-V nanocomposite at moderate temperatures. J. Phys. Chem. C 2014, 118, 22419-22425. [CrossRef]

7. Agueyzinsou, K.; Aresfernandez, J.; Klassen, T.; Bormann, R. Effect of $\mathrm{Nb}_{2} \mathrm{O}_{5}$ on $\mathrm{MgH}_{2}$ properties during mechanical milling. Int. J. Hydrogen Energy 2007, 32, 2400-2407. [CrossRef]

8. Friedrichs, O.; Aguey-Zinsou, F.; Fernández, J.R.A.; Sánchez-López, J.C.; Justo, A.; Klassen, T.; Bormann, R.; Fernández, A. $\mathrm{MgH}_{2}$ with $\mathrm{Nb}_{2} \mathrm{O}_{5}$ as additive, for hydrogen storage: Chemical, structural and kinetic behavior with heating. Acta Mater. 2006, 54, 105-110. [CrossRef] 
9. Ares-Fernandez, J.R.; Aguey-Zinsou, K.F. Superior $\mathrm{MgH}_{2}$ kinetics with $\mathrm{MgO}$ addition: A tribological effect. Catalysts 2012, 2, 330-343. [CrossRef]

10. Aguey-Zinsou, K.F.; Ares Fernandez, J.R.; Klassen, T.; Bormann, R. Using MgO to improve the (de)hydriding properties of magnesium. Mater. Res. Bull. 2006, 41, 1118-1126. [CrossRef]

11. Pundt, A. Hydrogen in nano-sized metals. Adv. Eng. Mater. 2004, 6, 11-21. [CrossRef]

12. De Jongh, P.E.; Wagemans, R.W.P.; Eggenhuisen, T.M.; Dauvillier, B.S.; Radstake, P.B.; Meeldijk, J.D.; Geus, J.W.; de Jong, K.P. The preparation of carbon-supported magnesium nanoparticles using melt infiltration. Chem. Mater. 2007, 19, 6052-6057. [CrossRef]

13. Zlotea, C.; Oumellal, Y.; Hwang, S.J.; Ghimbeu, C.M.; de Jongh, P.E.; Latroche, M. Ultrasmall $\mathrm{MgH}_{2}$ nanoparticles embedded in an ordered microporous carbon exhibiting rapid hydrogen sorption kinetics. J. Phys. Chem. C 2015, 119, 18091-18098. [CrossRef]

14. Zhao-Karger, Z.; Hu, J.; Roth, A.; Wang, D.; Kubel, C.; Lohstroh, W.; Fichtner, M. Altered thermodynamic and kinetic properties of $\mathrm{MgH}_{2}$ infiltrated in microporous scaffold. Chem. Commun. 2010, 46, 8353-8355. [CrossRef] [PubMed]

15. Zlotea, C.; Latroche, M. Role of nanoconfinement on hydrogen sorption properties of metal nanoparticles hybrids. Colloids Surf. A Physicochem. Eng. Asp. 2013, 439, 117-130. [CrossRef]

16. Smith, B.; Wepasnick, K.; Schrote, K.E.; Cho, H.H.; Ball, W.P.; Fairbrother, D.H. Influence of surface oxides on the colloidal stability of multi-walled carbon nanotubes: A structure-property relationship. Langmuir 2009, 25, 9767-9776. [CrossRef] [PubMed]

17. Lai, Q.; Christian, M.; Aguey-Zinsou, K.-F. Nanoconfinement of borohydrides in CuS hollow nanospheres: A new strategy compared to carbon nanotubes. Int. J. Hydrogen Energy 2014, 39, 9339-9349. [CrossRef]

18. Haas, I.; Gedanken, A. Synthesis of metallic magnesium nanoparticles by sonoelectrochemistry. Chem. Commun. 2008, 1795-1797. [CrossRef] [PubMed]

19. Viyannalage, L.; Lee, V.; Dennis, R.V.; Kapoor, D.; Haines, C.D.; Banerjee, S. From Grignard's reagents to well-defined Mg nanostructures: Distinctive electrochemical and solution reduction routes. Chem. Commun. 2012, 48, 5169-5171. [CrossRef] [PubMed]

20. Aguey-Zinsou, K.-F.; Ares-Fernández, J.-R. Synthesis of colloidal magnesium: A near room temperature store for hydrogen. Chem. Mater. 2007, 20, 376-378. [CrossRef]

21. Connor, J.H.; Reid, W.E.; Wood, G.B. Electrodeposition of metals from organic solutions v. electrodeposition of magnesium and magnesium alloys. J. Electrochem. Soc. 1957, 104, 38-41. [CrossRef]

22. Gaddum, L.W.; French, H.E. The electrolysis of Grignard solution. J. Am. Chem. Soc. 1927, 49, 1295-1299. [CrossRef]

23. French, H.E.; Drane, M. Electrolysis of Grignard solutions. J. Am. Chem. Soc. 1930, 52, 4904-4906. [CrossRef]

24. Jolibois, P. On the formula of the organo-magnesian derivative and on the magnesium hydride. C. R. Hebd. Seances Acad. Sci. 1912, 155, 353-355.

25. Aurbach, D.; Turgeman, R.; Chusid, O.; Gofer, Y. Spectroelectrochemical studies of magnesium deposition by in situ FTIR spectroscopy. Electrochem. Commun. 2001, 3, 252-261. [CrossRef]

26. Setijadi, E.J.; Boyer, C.; Aguey-Zinsou, K.-F. $\mathrm{MgH}_{2}$ with different morphologies synthesized by thermal hydrogenolysis method for enhanced hydrogen sorption. Int. J. Hydrogen Energy 2013, 38, 5746-5757. [CrossRef]

27. Aurbach, D.; Gizbar, H.; Schechter, A.; Chusid, O.; Gottlieb, H.E.; Gofer, Y.; Goldberg, I. Electrolyte solutions for rechargeable magnesium batteries based on organomagnesium chloroaluminate complexes. J. Electrochem. Soc. 2002, 149, A115-A121. [CrossRef]

28. Oniciu, L.; Muresan, L. Some fundamental-aspects of leveling and brightening in metal electrodeposition. J. Appl. Electrochem. 1991, 21, 565-574. [CrossRef]

29. Hanada, N.; Ichikawa, T.; Fujii, H. Catalytic effect of nanoparticle 3d-transition metals on hydrogen storage properties in magnesium hydride $\mathrm{MgH}_{2}$ prepared by mechanical milling. J. Phys. Chem. B 2005, 109, 7188-7194. [CrossRef] [PubMed]

30. Liu, Y.; Zou, J.; Zeng, X.; Wu, X.; Li, D.; Ding, W. Hydrogen storage properties of a Mg-Ni nanocomposite coprecipitated from solution. J. Phys. Chem. C 2014, 118, 18401-18411. [CrossRef]

31. Minachev, K.M.; Dmitriev, R.V.; Rustamov, M.I.; Kasimov, C.K.; Abad-zade, K. Thermal desorption of hydrogen from supported nickel catalysts. Bull. Acad. Sci. USSR Divis. Chem. Sci. 1981, 30, 1170-1176. [CrossRef] 
32. Christmann, K.; Schober, O.; Ertl, G.; Neumann, M. Adsorption of hydrogen on nickel single crystal surfaces. J. Phys. Chem. 1974, 60, 4528-4540. [CrossRef]

33. Wright, S.; Skelly, J.F.; Hodgson, A. Energy disposal during desorption of $\mathrm{D}_{2}$ from the surface and subsurface region of Ni(111). Faraday Discuss. 2000, 117, 133-146. [CrossRef]

34. Li, T.; Ma, G.H.; Sun, H.J. Ammonia-alkali solution coordination-precipitation route for preparation of beta-Ni(OH)$)_{2}$ nano-particles. Rare Met. Mater. Eng. 2014, 43, 563-566. [CrossRef]

35. Fry, C.M.P.; Grant, D.M.; Walker, G.S. Catalysis and evolution on cycling of nano-structured magnesium multilayer thin films. Int. J. Hydrogen Energy 2014, 39, 1173-1184. [CrossRef]

36. Shahi, R.R.; Tiwari, A.P.; Shaz, M.A.; Srivastava, O.N. Studies on de/rehydrogenation characteristics of nanocrystalline $\mathrm{MgH}_{2}$ co-catalyzed with Ti, Fe and Ni. Int. J. Hydrogen Energy 2013, 38, 2778-2784. [CrossRef]

37. Li, P.; Wan, Q.; Li, Z.; Zhai, F.; Li, Y.; Cui, L.; Qu, X.; Volinsky, A.A. $\mathrm{MgH}_{2}$ dehydrogenation properties improved by $\mathrm{MnFe}_{2} \mathrm{O}_{4}$ nanoparticles. J. Power Sources 2013, 239, 201-206. [CrossRef]

38. Juahir, N.; Mustafa, N.S.; Sinin, A.M.; Ismail, M. Improved hydrogen storage properties of $\mathrm{MgH}_{2}$ by addition of $\mathrm{Co}_{2} \mathrm{NiO}$ nanoparticles. RSC Adv. 2015, 5, 60983-60989. [CrossRef]

39. Perejón, A.; Sánchez-Jiménez, P.E.; Criado, J.M.; Pérez-Maqueda, L.A. Magnesium hydride for energy storage applications: The kinetics of dehydrogenation under different working conditions. J. Alloys Compd. 2016, 681, 571-579. [CrossRef]

40. Yao, X.; Zhu, Z.H.; Cheng, H.M.; Lu, G.Q. Hydrogen diffusion and effect of grain size on hydrogenation kinetics in magnesium hydrides. J. Mater. Res. 2008, 23, 336-340. [CrossRef]

41. Langhammer, C.; Zhdanov, V.P.; Zorić, I.; Kasemo, B. Size-dependent kinetics of hydriding and dehydriding of Pd nanoparticles. Phys. Rev. Lett. 2010, 104, 135502. [CrossRef] [PubMed]

42. Baldé, C.P.; Hereijgers, B.P.C.; Bitter, J.H.; de Jong, K.P. Sodium alanate nanoparticles-Linking size to hydrogen storage properties. J. Am. Chem. Soc. 2008, 130, 6761-6765. [CrossRef] [PubMed]

43. Hoang, K.; Janotti, A.; van de Walle, C.G. The particle-size dependence of the activation energy for decomposition of lithium amide. Angew. Chem. Int. Ed. 2011, 50, 10170-10173. [CrossRef] [PubMed]

44. Mintz, M.H.; Zeiri, Y. Hydriding kinetics of powders. J. Alloys Compd. 1995, 216, 159-175. [CrossRef]

45. Hancock, J.D.; Sharp, J.H. Method of comparing solid-state kinetic data and its application to decomposition of kaolinite, brucite, and $\mathrm{BaCO}_{3}$. J. Am. Ceram. Soc. 1972, 55, 74-77. [CrossRef] 